\title{
The Effects of X-rays on the Progress of L-Cells through the Cell Cycle'
}

\author{
S. MAK $^{2}$ AND J. E. TILL \\ Department of Medical Biophysics, University of Toronto, and \\ The Ontario Cancer Institute, Toronto, Ontario
}

\section{INTRODUCTION}

It now appears well established that the key components of the genetic mechanism of cells are the macromolecular nucleic acids, and, in particular, macromolecular deoxyribonucleic acid (DNA). It is of considerable interest from a radiobiological point of view to study the effects of ionizing radiation on the functional capabilities of DNA, particularly that of self-replication, which must occur before every mitotic division of a cell. It has been suggested $(1,2)$ that the principal effect of radiation on the cell cycle of L-cells is on the progress of cells through the post-DNA synthesis $\left(G_{2}\right)$ period, though an effect of radiation on the progress of cells through the DNA synthesis period was also observed (2). Since it has been shown in a number of mammalian cell systems that DNA synthesis may be suppressed immediately after irradiation (see, for example, ref. 3-7), it was of interest to study in more detail the effects of radiation on the DNA synthesis period of L-cells.

The time relationship between DNA synthesis and mitosis for exponentially multiplying strain-L mouse cells in suspension culture has been determined (8). The approximate durations of the periods of the cell cycle are as follows: mitosis $(M)$ is approximately 1 hour; $G_{1}$ is $9.0 \pm 3.3$ hours; the DNA synthesis period $(S)$ is $7.0 \pm 1.3$ hours; and $G_{2}$ is $3.0 \pm 0.7$ hours. (The notation is that of Howard and Pelc, 9.)

In this investigation, the effects of $\mathrm{X}$-rays on the progress of strain-L mouse cells in tissue culture from $G_{1}$ to $S$, through $S$ and from $S$ to $G_{2}$ in the first-division cycle after irradiation were studied at the cellular level. The dose of $\mathrm{X}$-rays ranged from 580 to 10,900 rads. The data to be presented indicate that X-radiation has

\footnotetext{
${ }^{1}$ This paper is based on a thesis submitted in conformity with the requirements for the degree of Doctor of Philosophy in the University of Toronto.

${ }^{2}$ Present address: Biology Department, Queen's University, Kingston, Ontario.
} 
a variable effect on the progress of L-cells through each of the various parts of the division cycle.

\section{MATERIALS AND METHODS}

Cells

The cell line used, termed L60TM, was derived from L60 (1), a subline of Earle's L-cells. The L60TM subline has been adapted to grow in a medium without exogenous thymidine. The medium was CMRL 1066 (10) lacking thymidine and coenzymes, supplemented with $10 \%$ horse serum and antibiotics. Some properties of the L60TM subline differ from those of the L60. The mean chromosome number is only 55, compared with 60 for the L60, and the survival curve of proliferative capacity is characterized by a $D_{0}$ dose (11) of 145 rads and an extrapolation number of 9 , in contrast with a $D_{0}$ dose of 240 rads and an extrapolation number of 2 for the L60 line (1). The cells were cultured in suspension at $37^{\circ} \mathrm{C}$ in either roller tubes or spinner flasks $(10)$. These cultures were kept in the logarithmic growth phase by periodic dilution with fresh medium at $37^{\circ} \mathrm{C}$. Under these conditions, the average doubling time varied from 18 to 25 hours.

\section{Detection of DNA Synthesis}

The rate of DNA synthesis in control and irradiated cell populations was estimated by measuring the incorporation of $\mathrm{I}^{125}$-labeled 5 -iodo- $\mathbf{2}^{\prime}$-deoxyuridine $\left(\mathrm{I}^{\mathbf{1 2 5}}\right.$ UDR), which is an analog of thymidine (TDR) (12). Five-milliliter aliquots of a master culture were removed at various times and incubated with $\mathrm{I}^{125}$ UDR for 50 minutes, whereupon they were fixed by the addition of $0.2 \mathrm{ml}$ of $37 \%$ formaldehyde solution, and the cells were sedimented by centrifugation at $1300 \times g$ for 10 minutes. The acid-soluble materials were removed by two successive extractions with $0.3 \mathrm{~N}$ perchloric acid $(\mathrm{PCA})$ at $0^{\circ} \mathrm{C}$. The $\gamma$-rays from $\mathrm{I}^{125}$ were detected by a $\gamma$-ray scintillation counter (Nuclear Chicago, Model C120). The total DNA contents of cell samples were determined by the diphenylamine method (13).

\section{Irradiation Procedure}

The X-ray source was a Picker 280-kvp machine operating at 20 ma with added filtration to yield a HVL of $1.12 \mathrm{~mm} \mathrm{Cu}$. Cell suspensions were irradiated at a concentration of about $10^{5}$ cells $/ \mathrm{ml}$ in a large spinner flask (1-liter volume) immersed in a temperature-controlled water bath. The radiation dose was delivered in successive fractions. After each increment of dose, an aliquot was transferred to a small spinner flask $(250-\mathrm{ml}$ volume $)$. The remainder of the culture was then exposed to another increment of radiation dose, the time interval between successive fractions being less than 5 minutes. During and after irradiation, the cells were kept in suspension by continuous mixing. The cell cultures were kept at $37^{\circ} \mathrm{C}$ at all times. 
The average absorbed dose delivered to the cells was determined by means of the ferrous ammonium sulfate dosimeter (14). The dose rate varied from 170 to 185 $\mathrm{rads} / \mathrm{min}$, depending on the volume of cells in the spinner flask.

\section{Cell Counts}

Cell concentrations of cultures were determined by means of an automatic cell counter (Coulter counter).

\section{Autoradiography}

The methods used for autoradiography of cells labeled with $H^{3}$-thymidine $\left(\mathrm{H}^{3} \mathrm{TDR}\right)$ have been described previously $(8) . \mathrm{H}^{3} \mathrm{TDR}$ was obtained from the New England Nuclear Co., Boston.

\section{RESULTS}

Inhibition of Cell Division by Radiation

Figure 1 shows the cell concentration as a function of time for a nonirradiated culture and for a culture which had received 5570 rads. It can be seen that the non-

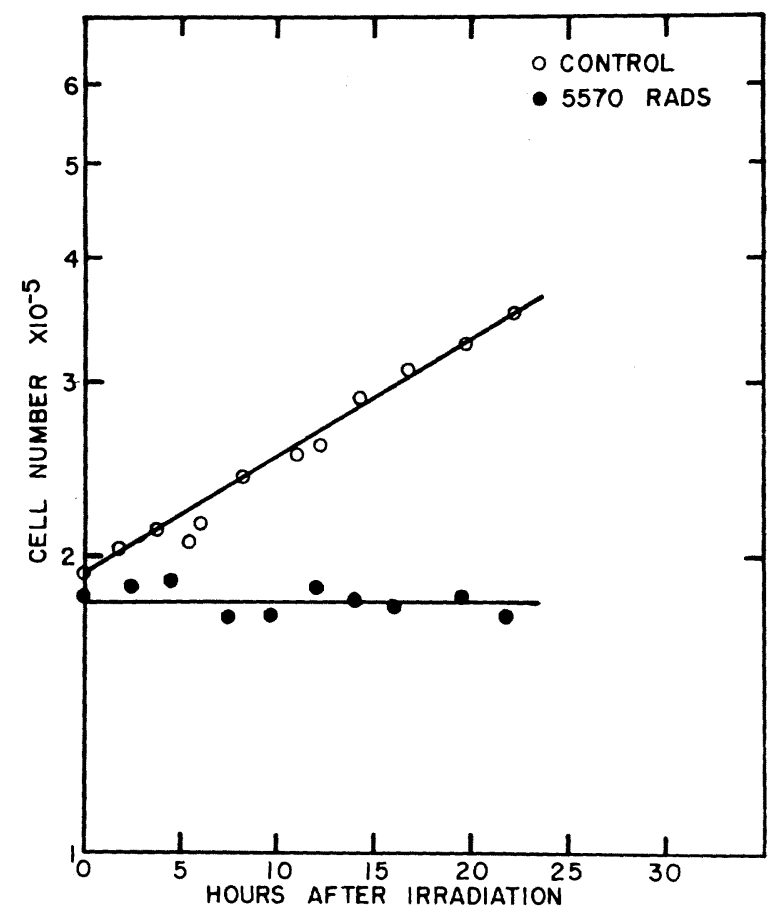

Frg. 1. Growth curve of a control culture and a culture irradiated with $\mathbf{5 5 7 0}$ rads 
irradiated culture multiplied exponentially while the cell count of the irradiated culture remained constant for the entire duration of the experiment (20 hours). The growth curves for cultures which had received the other doses of X-rays used were similar to the one irradiated with 5570 rads.

Progress of Cells from $G_{1}$ to $S$ after Irradiation

The flow of cells from $G_{1}$ to $S$ was studied by determining the fraction of the cells in a culture that had incorporated $\mathrm{H}^{3} \mathrm{TDR}$ at different times after the addition of $\mathrm{H}^{3} \mathrm{TDR}$ to the culture, for continuous exposure to the label. The fraction of cells that had incorporated $\mathrm{H}^{3} \mathrm{TDR}$ was determined by autoradiography.

For each experiment, cells from a single culture were irradiated with different doses of X-rays ( 580 to $10,900 \mathrm{rads}$ ), after a portion of the culture had been set aside as control. Immediately prior to irradiation, $\mathrm{H}^{3} \mathrm{TDR}$ at a specific activity of $0.03 \mu \mathrm{c} / \mu \mathrm{g}$ was added to the culture to a level of $0.012 \mu \mathrm{c} / \mathrm{ml}$. At different times after irradiation, cell samples were removed and autoradiographs were prepared. After the autoradiographs were developed and fixed, they were scored for the percentage of cells showing the presence of label. The results of a typical experiment are presented in Fig. 2, showing the percentage of labeled cells as a function of time for a control culture and a culture irradiated with 5570 rads.

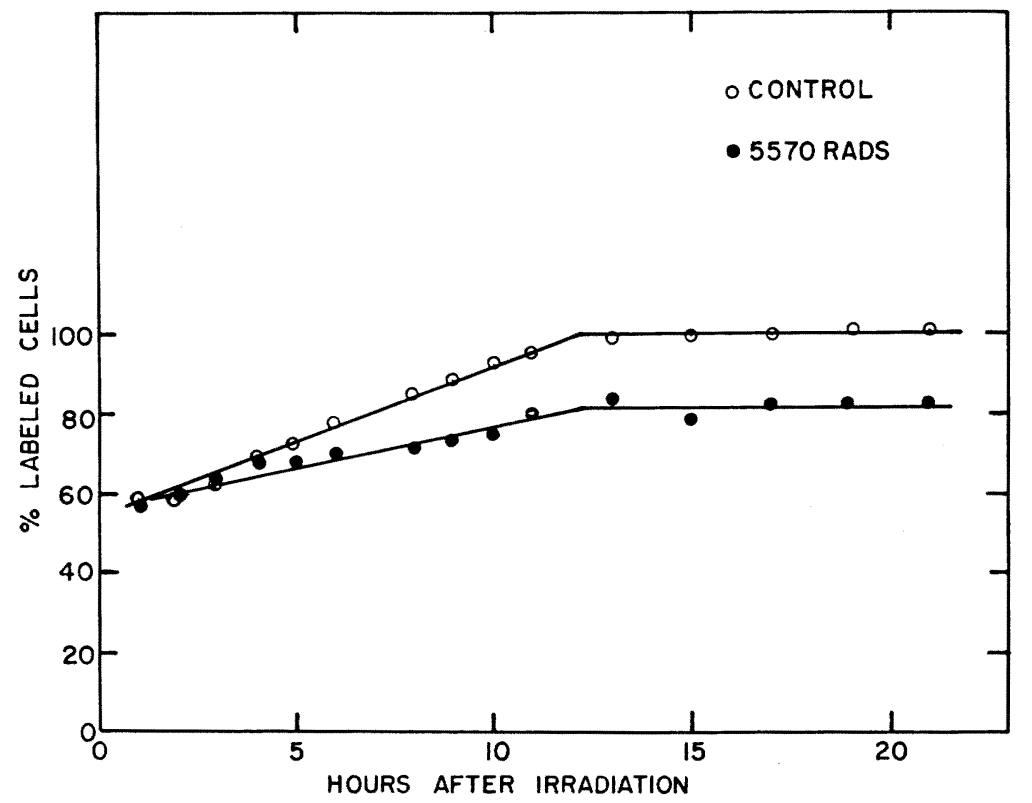

FIG. 2. The percentage of cells which have incorporated $H^{8} T D R$ in a control culture and in a culture irradiated with $\mathbf{5 5 7 0}$ rads, as a function of time after irradiation. $\mathbf{H}^{\mathbf{3}} \mathrm{TDR}$ was added $\mathbf{3 0}$ minutes before the completion of irradiation. 
It can be seen that the percentage of labeled cells in the control culture increased with time, indicating that cells flowed from $G_{1}$ to $S$, thus becoming labeled with $\mathrm{H}^{3} \mathrm{TDR}$. At about 12 hours after the addition of $\mathrm{H}^{3} \mathrm{TDR}$ the percentage of labeled cells reached $100 \%$. For the irradiated culture, the percentage of labeled cells also increased as a function of time, but at a slower rate, and reached a maximum of $80 \%$ instead of $100 \%$. This reduction in the maximum value may be attributed to the effects of the mitotic block induced by radiation (1). It has been suggested that this block occurs immediately prior to mitosis and prevents cells from leaving $G_{2}$ to enter mitosis, but allows cells initially in $G_{1}$ to enter $S$. Therefore, when the last cell in $G_{1}$ has entered $S$, the increase in the percentage of labeled cells ceases. The cells initially in $G_{2}$ at the time of irradiation cannot enter $S$ until the mitotic block is overcome; therefore, the percentage of labeled cells in an irradiated culture levels off at a value less than $100 \%$.

Measurements of the rate of flow of cells from $G_{1}$ to $S$, estimated by the slope of the linear portion of curves similar to that shown in Fig. 2, are shown in Table $\mathrm{I}$ for cultures irradiated with different doses of X-rays. The values are expressed as per cent of the control rate. It can be seen that the rate of flow of cells from $G_{1}$ to $S$ was affected to the same extent for doses ranging from 580 to 10,900 rads.

The lack of evidence of any dependence on dose in the range from 580 to 10,900 rads in the data of Table I suggested that an experiment be carried out at a lower dose level. Therefore, the rate of flow of cells from $G_{1}$ to $S$ after a dose of 220 rads was compared with that of a control culture. It was found that the rate of flow of cells from $G_{1}$ to $S$ was only $80 \%$ of the control rate, i.e., intermediate between the control rate of flow and the rate observed for cultures irradiated with 580 to 10,900 rads.

These results suggest that the rate of flow of cells from $G_{1}$ to $S$ is reduced by $\mathrm{X}$-rays, and that there is a maximum reduction in the rate of entry from $G_{1}$ to $S$ $(50 \%)$ which was achieved by a dose of 580 rads or greater. These results rule out the possibility that radiation induces a block at the beginning of $S$, thus preventing

TABLE I

Effect of Radiation on the Progress of Cells from $G_{1}$ into $S$

\begin{tabular}{rccccc}
\hline \multirow{2}{*}{$\begin{array}{c}\text { Dose } \\
\text { (rads })\end{array}$} & \multicolumn{5}{c}{ Rate of flow from $G_{1}$ to $S(\%$ of control) } \\
\cline { 2 - 6 } & Expt.1 & Expt.2 & Expt.3 & Expt. 4 & Avg. \\
\hline 220 & - & - & - & 80 & 80 \\
580 & 61 & 55 & 46 & - & 54 \\
1,160 & 57 & 52 & 49 & - & 53 \\
2,290 & 64 & 52 & 40 & - & 52 \\
5,570 & 64 & 50 & 49 & - & 54 \\
10,900 & 70 & 44 & 46 & - & 53 \\
\hline
\end{tabular}


cells from entering the $S$ period, since there was a continuous flow of cells from $G_{1}$ to $S$. The observation that $80 \%$ of the cells in the irradiated cultures could become labeled indicates that nearly all the cells irradiated in $G_{1}$ are able to enter the subsequent $S$ period, since the $20 \%$ of cells which did not incorporate $\mathrm{H}^{3} \mathrm{TDR}$ were probably those trapped in $G_{2}$ by the radiation-induced mitotic block (1).

The percentage of labeled cells in a culture under continuous incubation with $\mathrm{H}^{3} \mathrm{TDR}$ may be increased by the flow of cells from $G_{1}$ to $S$ and by the division of labeled cells. On the other hand, it can be decreased by division of nonlabeled cells if the flow of cells from $G_{1}$ to $S$ is absent. In the study of the flow of cells from $G_{1}$ to $S$ after irradiation, the percentage of labeled cells in a multiplying control culture was compared with those of nonmultiplying irradiated cultures; therefore the observed percentage of labeled cells in the nonirradiated control culture should be corrected to what would have been observed had no multiplication taken place (8). If this were carried out, the rate of flow of cells from $G_{1}$ to $S$ in the control culture would be slightly greater than that shown in Fig. 2. For this reason, the experimental results, as shown, represent a slight underestimate of the effects of radiation on the flow of cells from $G_{1}$ to $S$.

\section{Progress of Cells Through the S Phase after Irradiation}

Inhibition of the rate of DNA synthesis. The rate of DNA synthesis by the cells of an irradiated culture may be used as a measure of the rate of progress of cells through the $S$ phase after irradiation. In the experiments reported here, the uptake of $\mathrm{I}^{125} \mathrm{UDR}$ into DNA was used as a measure of the rate of DNA synthesis. To obtain evidence that the method used provided a valid measure of the rate of DNA synthesis, the integrated rate of uptake of $I^{125}$ UDR into DNA was compared with the total DNA content of the culture, determined by the diphenylamine method (13), at various times after irradiation. This comparison was made because a reduction in the rate of uptake of $\mathrm{I}^{125} \mathrm{UDR}$ into DNA after irradiation might not represent an actual reduction in the rate of DNA synthesis but might be due to other effects of radiation on cellular metabolism.

In the absence of such complicating factors, the relationship between the rate of uptake of $\mathrm{I}^{125} \mathrm{UDR}$ and the total DNA content of the culture would be expected to be as follows:

$$
(\mathrm{DNA})_{t}=k \int_{0}^{t} I\left(t^{\prime}\right) d t^{\prime}+(\mathrm{DNA})_{0}
$$

where $(\mathrm{DNA})_{t}$ is the DNA content of a culture at time $t$.

$(\mathrm{DNA})_{0}$ is the DNA content of a culture at time zero.

$I\left(t^{\prime}\right)$ is the rate of uptake of $I^{125} \mathrm{UDR}$ into DNA at time $t^{\prime}$.

$k$ is a conversion factor from $\mathrm{I}^{125}$ activity to amount of newly synthesized DNA per culture. 
Figure 3 shows the results of a test of this relationship. The value of $k$ for this experiment was determined by comparing the increase in the total DNA content of the control culture with the increase in the integrated uptake of $\mathrm{I}^{125} \mathrm{UDR}$ into the same culture during the 18-hour duration of the experiment. The data shown in Fig. 3 are expressed relative to the initial value of the control; i.e., (DNA) 0 has been set equal to unity. It may be seen from Fig. 3 that reasonable agreement between the two sets of results was obtained, which supports the view that measurements of the uptake of $I^{125} \mathrm{UDR}$ may be used as the basis for reliable determinations of the rate of DNA synthesis in irradiated cells. As has been pointed out by others (15), the results of precursor uptake measurements into irradiated

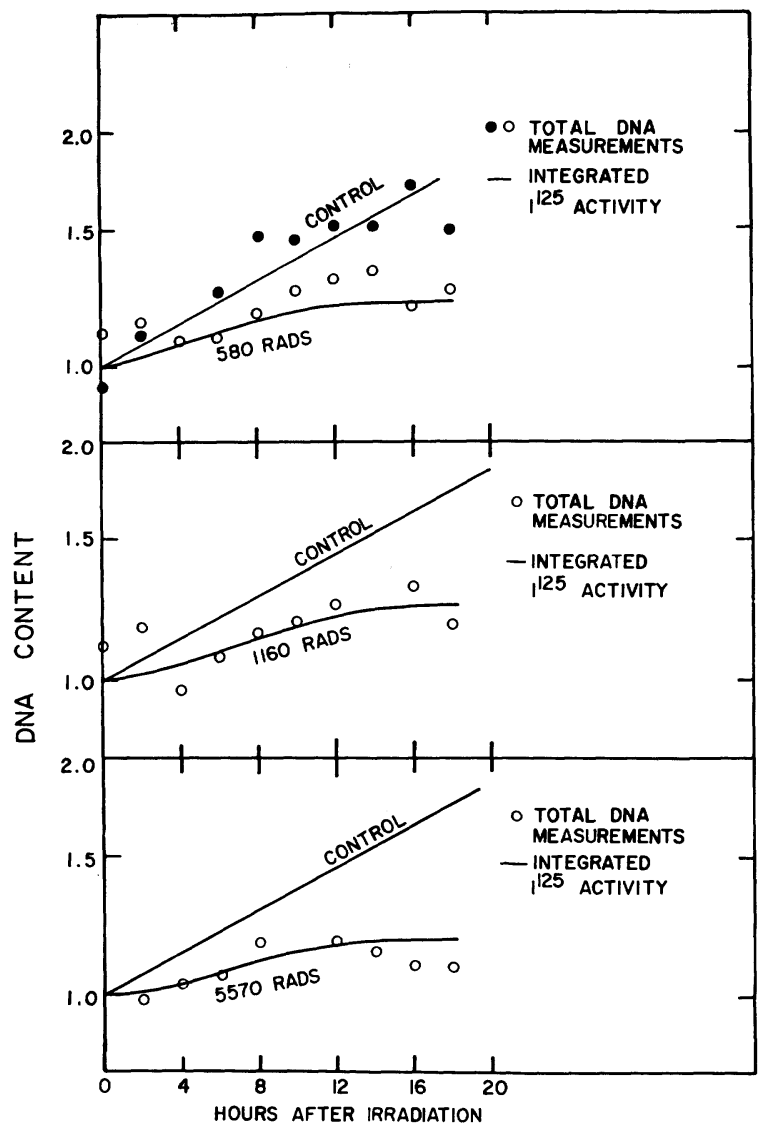

Fig. 3. DNA content per culture relative to the control at the time of irradiation, in a control culture and in three irradiated cultures. The DNA content was measured by two methodscolorimetrically by the diphenylamine method (13), and by integration of the rates of uptake of $\mathrm{I}^{125} \mathrm{UDR}$ into DNA. 
cells may, under certain circumstances, be difficult to interpret, owing to such factors as changes in precursor pool sizes after irradiation. The results presented in Fig. 3 suggest that this was not the case for the conditions used in the experiments reported here. Further results supporting this view have been described in detail elsewhere. ${ }^{3}$

Inhibition of $H^{3} T D R$ uptake. The results presented in Fig. 3 show that the rate of DNA synthesis is decreased in the cells of an irradiated L-cell population. In order to study this effect at the cellular level, it is necessary to measure the fraction of the cells in the population that are synthesizing DNA, so that a determination of the rate of DNA synthesis per DNA-synthesizing cell may be made. It is also necessary to demonstrate that changes in the average rate of uptake of label by DNA-synthesizing cells are due to changes in the rates of DNA synthesis of all the synthesizing cells, and are not due to DNA synthesis being almost completely suppressed in some cells of the population while synthesis continues at the normal rate in the remainder of the population. It is possible to distinguish between these two possibilities by determining the grain count over individual cells in autoradiographs prepared with cells pulse-labeled with $\mathrm{H}^{3} \mathrm{TDR}$ after irradiation. The grain counts over individual cells provide a measure of the rate of DNA synthesis by these cells. The results of such an experiment are shown in Fig. 4. In this figure, grain count distributions are presented for cells labeled with $\mathrm{H}^{3} \mathrm{TDR}$ at 1 hour after doses of 580 and 1160 rads, compared with the distribution for the unirradiated control cells. These distributions are presented in the form of cumulative distributions on a probability plot. A straight line on such a plot is characteristic of a normal distribution. The slope of the line is related to the standard deviation of the distribution. The results shown in the figure indicate that both control and irradiated cell populations show a normal distribution of grain counts. The mean of the distribution for the irradiated cells is shifted toward a lower grain count value, which indicates inhibition of DNA synthesis per cell in the synthesis phase. The results shown in Fig. 4 are summarized in Table II. Comparison of the coefficients of variation of the grain count distributions for the control and irradiated populations, made with the $F$ test (16), indicated that the breadths of the distributions were significantly greater in the irradiated populations. This finding is compatible with the view that all cells may be affected by the radiation, but to different extents. This hypothesis will be considered more fully below.

Time dependence of the inhibition of DNA synthesis. The data shown in Fig. 4 demonstrated that a depression in the rate of DNA synthesis in individual L-cells was detectable by 1 hour after irradiation. In order to study the time dependence of this effect, the I'125.UDR uptake method described above was utilized to study the rate of DNA synthesis as a function of time after irradiation, for a range of radia-

\footnotetext{
${ }^{3} \mathrm{~S}$. Mak, The effects of X-rays on the progress of mammalian cells through the division cycle in vitro. Ph.D. thesis, University of Toronto, 1962.
} 


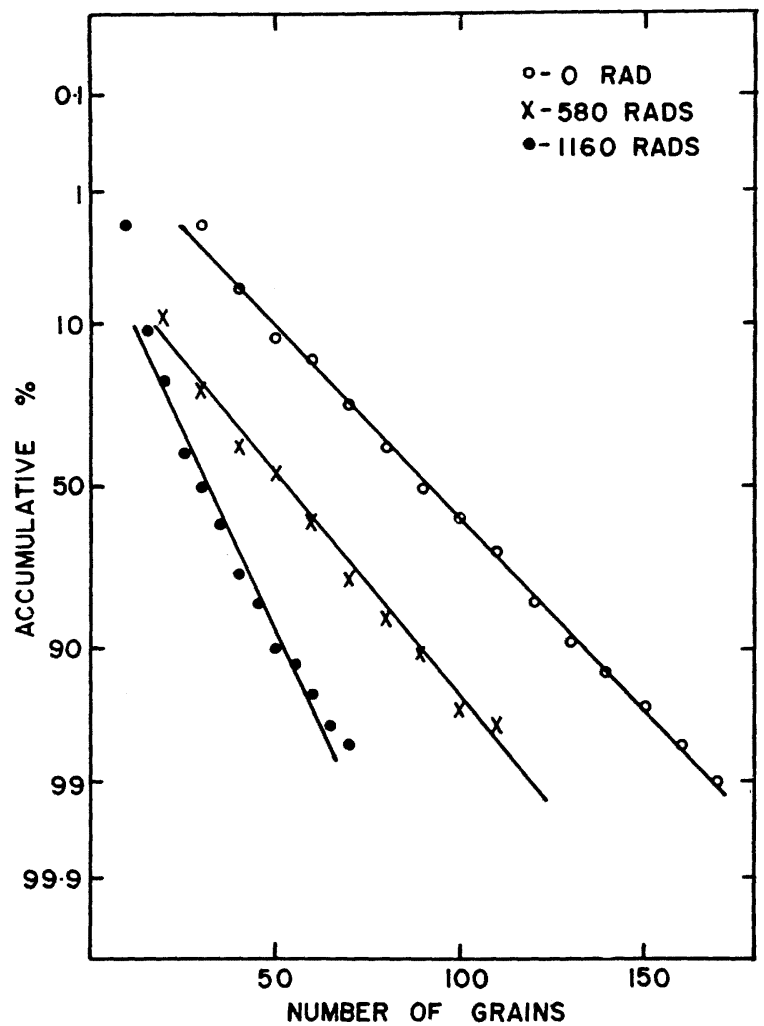

FIG. 4. Grain count distributions over labeled cells in autoradiographs of cells incubated with $\mathrm{H}^{2} \mathrm{TDR}$ at $1 \mu \mathrm{c} / \mathrm{ml}$ (specific activity $2 \mu \mathrm{c} / \mu \mathrm{g}$ ) for 50 minutes beginning 1 hour after irradiation. The ordinate gives the percentage of cells showing grain counts up to and including the abscissa grain count values, on a probability plot. A normal distribution appears as a straight line with its mean at the $\mathbf{5 0 \%}$ intercept.

TABLE II

Grain Counts over Labeled Cells in Autoradiographs

\begin{tabular}{rccccc}
\hline $\begin{array}{c}\text { Dose } \\
(\text { rads })\end{array}$ & $\begin{array}{c}\text { Mean grain } \\
\text { count per } \\
\text { labeled cell }\end{array}$ & $\begin{array}{c}\text { Standard } \\
\text { deviation }\end{array}$ & $\begin{array}{c}\text { Coefficient of } \\
\text { variation }\end{array}$ & $F$ & $P$ \\
\hline 0 & 90 & 33 & 0.37 & - & - \\
580 & 52 & 28 & 0.54 & 2.2 & $<0.001$ \\
1160 & 31 & 16 & 0.52 & 2.0 & $<0.001$ \\
2290 & 25 & 15 & 0.60 & 2.7 & $<0.001$ \\
\hline
\end{tabular}

a 100 cells were counted for each dose. 
tion doses. The procedure used in these experiments was as follows: At various times after irradiation, aliquots were removed from the culture and incubated with shaking for 50 minutes at $37^{\circ} \mathrm{C}$ with $\mathrm{I}^{125} \mathrm{UDR}$ at about $1 \mu \mathrm{c} / \mathrm{ml}$ (specific activity approximately $0.3 \mu \mathrm{c} / \mu \mathrm{g}$ ) and with $\mathrm{H}^{3} \mathrm{TDR}$ at $2 \mu \mathrm{c} / \mathrm{ml}$ (specific activity $4 \mu \mathrm{c} / \mu \mathrm{g})$. After incubation, determinations were made of the $\mathrm{I}^{125}$ activity incorporated into DNA, the percentage of cells labeled with $\mathrm{H}^{3} \mathrm{TDR}$, and the number of cells in the aliquot. From these data, the average rate of DNA synthesis per synthesizing cell may be calculated, from the relation:

$$
R(t)=A F_{0} N_{0} / A_{0} F N
$$

where $R(t)$ is the average rate of DNA synthesis per DNA-synthesizing cell, relative to the unirradiated control at the time of irradiation.

$A$ is the activity in counts per minute of $\mathrm{I}^{\mathbf{1 2 5}}$ incorporated into cellular DNA after a 50-minute incubation of the cells in the presence of $\mathrm{I}^{125} \mathrm{UDR}$.

$F$ is the fraction of cells in the culture incorporating $\mathrm{H}^{3} \mathrm{TDR}$, when this compound was added to the culture together with $\mathrm{I}^{125} \mathrm{UDR}$, determined by autoradiography.

$N$ is the number of cells in the aliquot at time $t . A_{0}, F_{0}$, and $N_{0}$ are the corresponding (initial) values for the unirradiated control.

These rates of DNA synthesis, expressed as per cent of the control rate, at various times after different doses of X-rays, are shown in Fig. 5. It can be seen that $\mathrm{X}$-rays at the dose levels used depressed the rate of DNA synthesis. This depression occurred very shortly after irradiation. At $1 / 2$ hour after 10,900 rads, the DNA synthesis rate was only $38 \%$ of the control value. However, these rates increased with increasing time after irradiation for doses up to 5570 rads, indicating that there was an apparent recovery from the effects of radiation. The apparent recovery was greatest at the lowest dose level. At 18 hours after 580 rads the rate of DNA synthesis was almost the same as that of the control, whereas at the same time after 10,900 rads it was still only $40 \%$ of the control rate. The difference in the depression at different times after irradiation may be due to the fact that different populations were examined at different times; the depression measured immediately after irradiation was due to the cells in DNA synthesis at the time of irradiation, and that measured at later times, say 18 hours, was due mainly to the cells in $G_{1}$ at the time of irradiation. Thus the apparent recovery of the rate of DNA synthesis may be due to a repair process which went on while the cells progressed from $G_{1}$ to $S$. Alternatively, the rate of DNA synthesis of the cells irradiated in $G_{1}$ may not be so sensitive to the radiation as those in $S$. The data available do not allow one to distinguish between these possibilities.

It can be seen clearly from Fig. 5 that the depression of the rate of DNA synthesis was dose-dependent. This dose dependency is shown in Fig. 6, with the rate of DNA synthesis, expressed as per cent of the control value, plotted against 


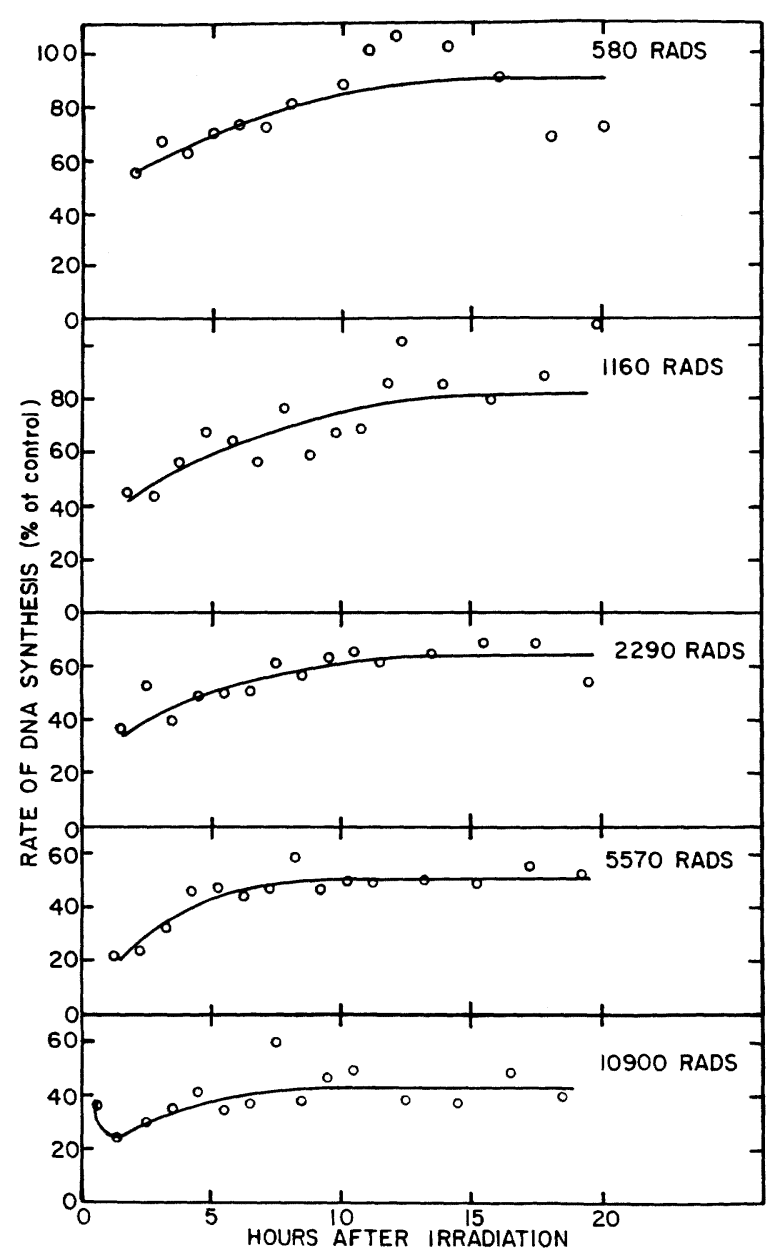

Fig. 5. The average rate of DNA synthesis per DNA-synthesizing cell, expressed as per cent of the rate in the unirradiated control, as a function of time after irradiation with the X-ray doses shown.

the logarithm of the radiation dose for two times after irradiation, 2 hours and 18 hours. It can be seen that the data for both times fall approximately along straight lines. The curve at 2 hours after irradiation represents the effects of radiation on the rate of DNA synthesis of the cells in $S$ at the time of irradiation; the 18-hour curve represents that of the cells irradiated in $G_{1}$. The lack of parallelism in these two lines indicates that the apparent recovery was not equal at all doses. The significance of this method of displaying the data will be discussed later.

An alternative method of displaying the dose-response curve is to use the more 


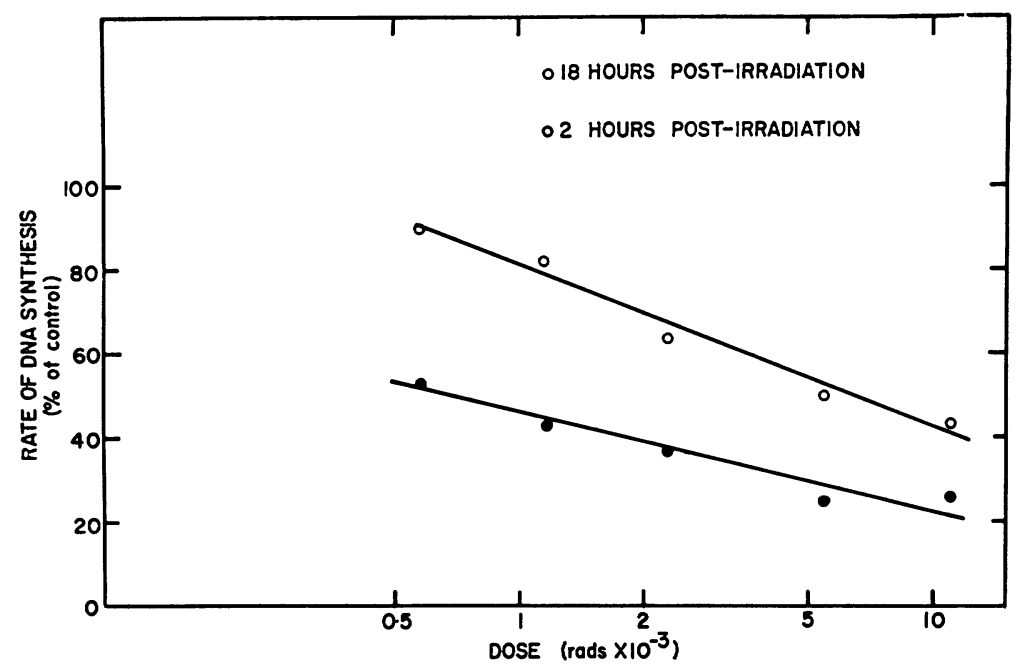

Fig. 6. The average rate of DNA synthesis per DNA-synthesizing cell, as a function of the logarithm of the X-ray dose, at 2 hours and at 18 hours after irradiation.

usual semilogarithmic plot. When this is done, these results appear to agree qualitatively with those of Lajtha et al. (4) and Painter (6), in that the slope of the curve decreases with increasing dose. These authors indicated that the doseresponse curve consisted of two exponential components. However, more than two exponential components are required in order to give a satisfactory fit to the present data.

Fraction of cells in S after irradiation. In the determination of the rate of DNA synthesis per synthesizing cell, the fraction, $F$, of cells which had incorporated $\mathrm{H}^{3} \mathrm{TDR}$ in the 50-minute incubation was measured. This time interval was short enough to give an estimate of the fraction of the cells in DNA synthesis at any given time. Some of the results of determinations of the percentage of cells in DNA synthesis obtained from a typical experiment are shown in Fig. 7 as a function of time after irradiation. For the sake of simplicity, the data from only two of the dose levels together with the control are shown. The results for other dose levels when plotted were intermediate between these two curves for the irradiated cultures.

For the nonirradiated exponentially multiplying control culture, the percentage of cells in DNA synthesis at any given time should be constant; however, the data indicate that it decreased as the experiment progressed. At the beginning of the experiment, approximately $50 \%$ of the cells were in DNA synthesis. It gradually decreased to a value of about $35 \%$. This decrease could be explained if the generation time of the culture increased throughout this particular experiment, but the duration of the $S$ period remained relatively constant. In the irradiated cultures, 


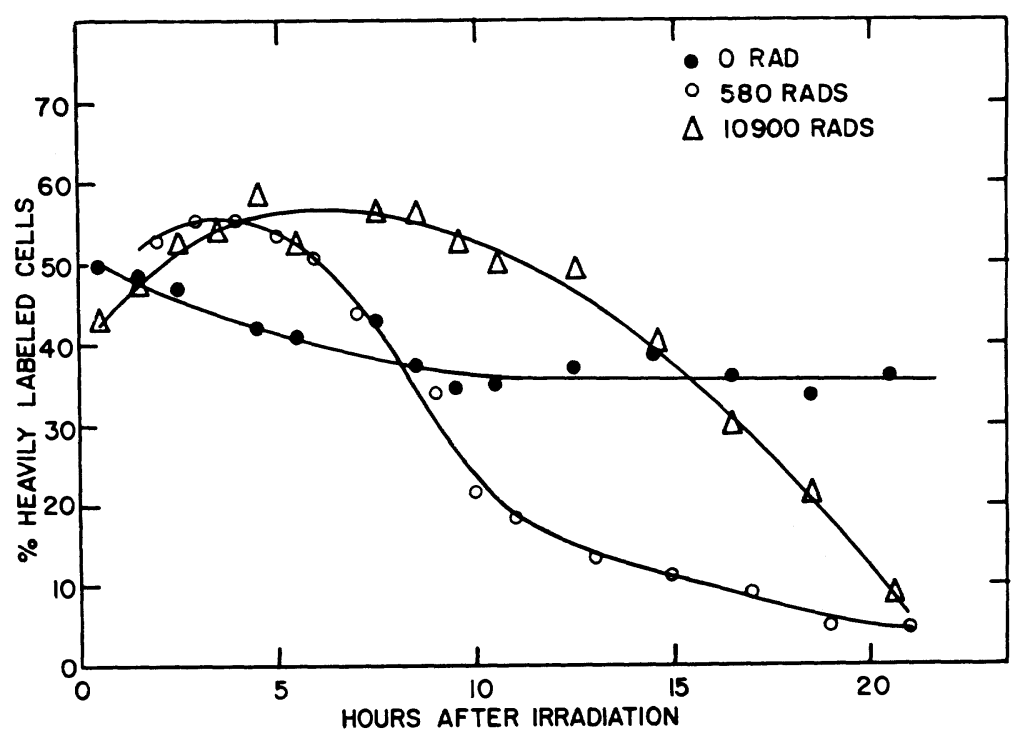

FIg. 7. The percentage of cells in DNA synthesis as a function of time, for a control culture and for cultures irradiated with 580 and 10,900 rads.

the percentage of cells in DNA synthesis at any given time increased for a period of several hours, giving rise to values greater that that of the nonirradiated control culture. The period in which the percentage of cells in DNA synthesis remained greater than the control value depended on the dose received, being longest for the highest dose. At later times, it gradually fell below the control value, and by 20 hours after 10,900 rads its value was only $10 \%$. These results confirm those of Painter and Robertson (17).

These results indicate that the rate of flow of cells out of $S$ was slower than the rate of flow of cells from $G_{1}$ into $S$ for a period of several hours, leading to an accumulation of cells in the $S$ phase. The number of cells in DNA synthesis later decreased because the mitotic block (1) prevented cells from entering $S$ after all the cells in $G_{1}$ had already moved into $S$. Since the rate of entry of cells from $G_{1}$ to $S$ was reduced by X-rays (see Fig. 2), the cells in DNA synthesis at the time of irradiation must have progressed out of $S$ at a slower rate in the irradiated culture than in the control culture.

\section{Progress of Cells from $S$ into $G_{2}$ after Irradiation}

The progress of cells from $S$ into $G_{2}$ was studied by a double-labeling technique. First, the cells in the $S$ period were lightly labeled by administering $\mathrm{H}^{3} \mathrm{TDR}$ at a low specific activity $(0.03 \mu \mathrm{c} / \mu \mathrm{g})$. This low level of $\mathrm{H}^{3} \mathrm{TDR}$ was left in the medium so that any cells entering $S$ at later times also became lightly labeled. 
Then, after various time intervals, aliquots from the culture were heavily labeled by the addition of a pulse of $\mathrm{H}^{3} \mathrm{TDR}$ at a high specific activity $(20 \mu \mathrm{c} / \mu \mathrm{g})$. Enough of this $\mathrm{H}^{3} \mathrm{TDR}$ was added to make the final specific activity in the medium of $4 \mu \mathrm{c} / \mu \mathrm{g}$. This heavily labeled all the cells still in the $S$ period at this time, but did not label cells that had left $S$ (i.e., completed DNA synthesis) during the time interval between the two additions of $\mathrm{H}^{3} \mathrm{TDR}$. These cells remained lightly labeled. The autoradiographs prepared from these cells could be scored for percentage of lightly labeled cells, which gave a measure of the progress of cells from $S$ into $G_{2}$. In practice, however, two sets of autoradiographs were prepared from each experiment. One set was exposed for a time short enough so that the lightly labeled cells had not yet produced any silver grains in the autoradiographs at the time when the heavily labeled one had given rise to an appreciable number of grains (50 to 100 grains per nucleus). The second set of slides was exposed for an extended period, so that all the labeled cells would have grain numbers well above the background. The percentage of labeled cells in these two sets of slides was determined, and the percentage of lightly labeled cells was obtained by subtraction. The method is illustrated in Fig. 8, which shows the results obtained as a function of time after a dose of 580 rads. The curve marked I-II represents the percentage of lightly labeled cells, which were the cells that had flowed from $S$ into $G_{2}$

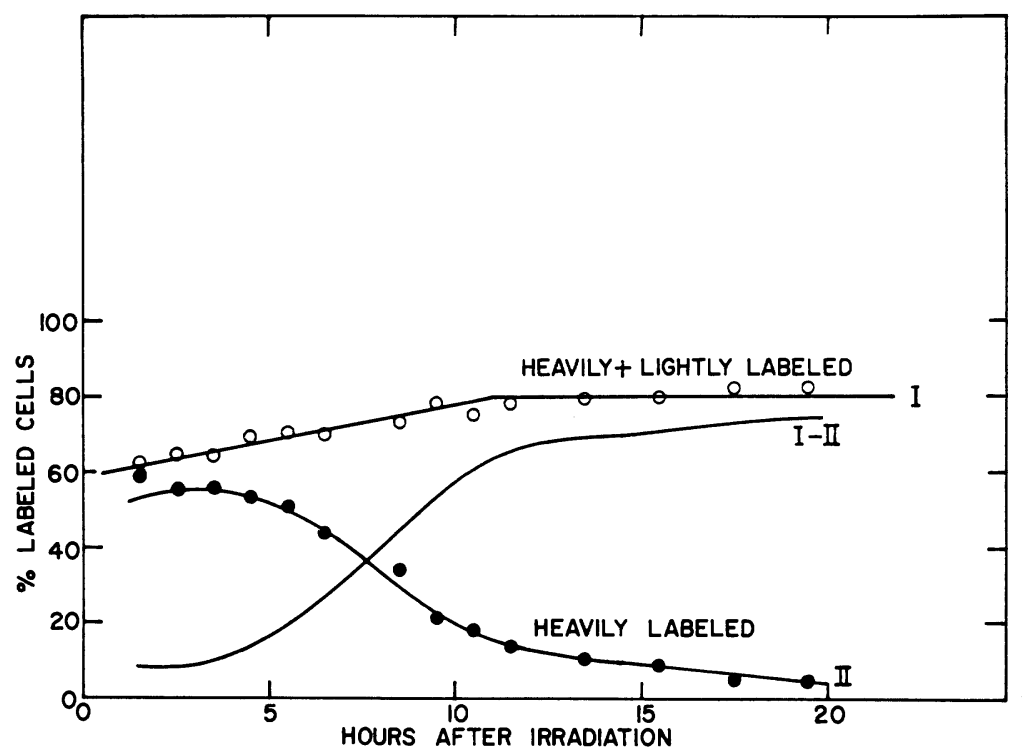

Fig. 8. An illustration of the method used to measure the flow of cells from the $S$ phase into the $G_{2}$ phase. Curve I-II, obtained by subtracting curve II from curve I, represents the percentage of cells that had progressed from $S$ into $G_{2}$ at various times after irradiation of the culture with 580 rads of $\mathrm{X}$-rays. 
after irradiation. A set of these curves obtained in a similar way from the results of a typical experiment are shown in Fig. 9. It can be seen that the percentage of lightly labeled cells increased with time in the nonirradiated culture, indicating flow of cells from $S$ to $G_{2}$. The percentage of cells that had flowed from $S$ to $G_{2}$ leveled off at $62 \%$. This is to be expected, since there was always approximately $40 \%$ of the cells in DNA synthesis at any given time, and these were heavily labeled by the pulse of high-specific-activity $\mathrm{H}^{3} \mathrm{TDR}$. For the irradiated cultures, the percentage of lightly labeled cells remained constant for several hours after the start of irradiation, indicating that no cells flowed from $S$ to $G_{2}$ in this period. This means that the cells in DNA synthesis at the time of irradiation were retained in $S$ for an abnormal length of time, confirming the conclusion drawn from the results shown in Fig. 7. The time interval where there was no apparent cell flow from $S$ to $G_{2}$ ( $S$ retention period) tended to be dose-dependent, with the longest retention at the highest dose level. The data obtained were not sufficiently precise to establish a quantitative relationship between the $S$ retention period and the radiation dose. After a temporary inhibition the cells began to flow from $S$ to $G_{2}$. Once this flow had begun, the rate of flow of cells from $S$ to $G_{2}$ in the cultures irradiated with doses in the range of 580 to 2290 rads was greater than that of the control. It should be noted that at $\mathbf{1 8}$ hours after the start of irradition (all doses) nearly all the labeled cells, which was about $80 \%$, were lightly labeled, indicating

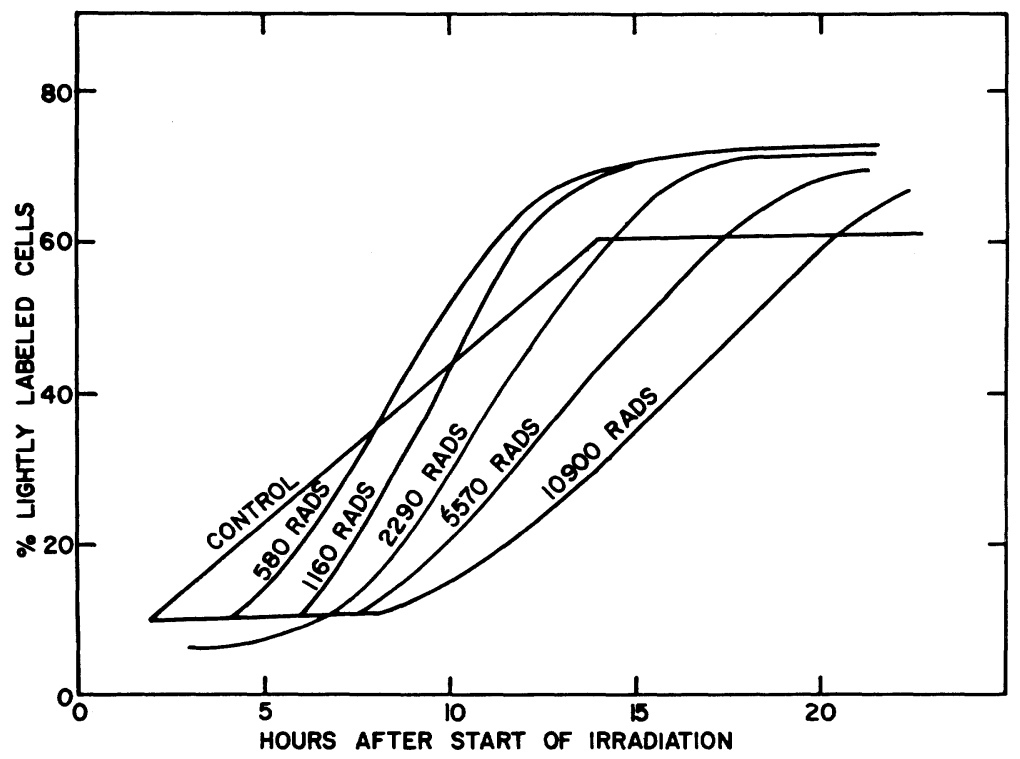

FIG. 9. The percentage of cells that had progressed from $S$ into $G_{2}$ as a function of time, for a control culture and for cultures irradiated with different doses of $\mathrm{X}$-rays. The individual curves were obtained by the method illustrated in Fig. 8 . 
that they were in $G_{2}$ at this time. The missing $20 \%$ of the cells may be assumed to have been trapped in $G_{2}$ by the mitotic inhibition, thus not becoming labeled. The finding that no cells flowed from $S$ to $G_{2}$ for several hours after irradiation agrees with results reported by Harrington (18).

In the measurement of the rate of flow of cells from $S$ to $G_{2}$, the results of determination of the percentage of lightly labeled cells after the addition of $\mathrm{H}^{3} \mathrm{TDR}$ to a multiplying culture was compared with the results obtained with nonmultiplying irradiated cultures. Therefore, the results for the control culture should be corrected for the contribution to the increase in the percentage of lightly labeled cells due to division of these labeled cells. This correction is not large enough to affect the interpretation of the results.

\section{DISCUSSION}

It may be seen from Fig. 1 that X-rays rapidly suppress cell multiplication in a logarithmic phase L-cell culture. It has been suggested that this immediate cessation of cell multiplication is due to a radiation-induced block in the $G_{2}$ period near mitosis $(1,18)$. This block prevents cells from entering mitosis but allows cells in other parts of the division cycle to continue their progress. The purpose of this investigation was to examine whether radiation induces a block exclusively in the $G_{2}$ period of L-cells or whether the progress of cells through other portions of the cycle is also affected. The results indicate that, for the subline of L-cells used in these experiments, doses in the range 580 to 10,900 rads affected the progress of cells through all parts of the division cycle. It should be pointed out that these radiation dose levels were supralethal in that the proliferative capacity of more than $90 \%$ of the cells of the irradiated populations had been destroyed.

These results indicate that the rate of flow of cells from $G_{1}$ to $S$ was reduced by $\mathrm{X}$-rays and that the maximal effect was produced by a dose of 580 rads or larger. Further increase of radiation dose up to 10,900 rads could produce no more reduction in the rate of flow from $G_{1}$ to $S$. Similar results were obtained by Lajtha and co-workers (19). Since there was a continuous flow of cells from $G_{1}$ to $S$, radiation did not induce a block at the beginning of $S$. The data presented suggest that nearly all the cells irradiated in $G_{1}$ could initiate DNA synthesis, but that the onset of DNA synthesis was delayed.

The rate of DNA synthesis per synthesizing cell was found to be depressed very shortly after irradiation in the dose range used in this investigation. This indicates that the rate of DNA synthesis of the cells irradiated in $S$ was depressed. At a later time, say 18 hours after irradiation, the depression on the rate of DNA synthesis was less (see Fig. 5). By 18 hours after irradiation, the cells engaged in DNA synthesis were mainly cells that were in the $G_{1}$ phase at the time of irradiation. This indicates that the rate of DNA synthesis of cells irradiated in $G_{1}$ was also affected, but to a lesser extent.

In an elegant series of experiments utilizing synchronously dividing HeLa S3 
cells, Terasima and Tolmach (20) have demonstrated that the ability of this cell strain to synthesize DNA is more sensitive to radiation damage when the cells are irradiated in the $S$ phase than when irradiated in other phases of the cell cycle. It is of interest that these authors also found the proliferative capacity of HeLa cells to be more sensitive to radiation when the cells were irradiated in late $G_{1^{-}}$ early $S$ than when irradiated in early $G_{1}$ or in $G_{2}$. Dewey and Humphrey (21) have shown that L-cells irradiated in the $S$ phase display a higher frequency of chromosomal aberrations than do those cells irradiated in $G_{1}$ or $G_{2}$. The molecular lesion (s) responsible for these various radiation responses remain to be identified.

Lajtha and co-workers (4) found that DNA synthesis of human bone marrow cells in culture was affected by radiation very shortly after irradiation. They suggested that the dose-response curve consists of two exponential components, one with a $D_{0}$ of $500 \mathrm{rads}\left(S_{1}\right)$ and the other with a $D_{0}$ of $13,000 \mathrm{rads}\left(S_{2}\right)$. They also suggested that the $S_{1}$ component represents part of the biochemical mechanism of precursor synthesis and that $S_{2}$ represents the integrity of DNA template (primer). This hypothesis does not seem to explain the results adequately, since both of these components (mechanism of precursor synthesis and DNA primer) are essential for the synthesis of DNA. If one component is inhibited, DNA synthesis cannot occur, although the other may still be intact. It is not possible for such a two-component curve to be obtained unless the sensitive component is not present, or is not utilized, or is rapidly repaired in some cells of the population.

It is noteworthy that the results of the experiments reported above indicate that the observed rate of DNA synthesis is a linear function of the logarithm of the radiation dose. It can easily be shown ${ }^{3}$ that this type of dose dependence may be obtained if it is assumed that the rate of DNA synthesis is linearly related to radiation dose for any population of cells in a small segment of $S$, and that each subpopulation of $S$-phase cells has a different sensitivity to radiation.

From the results shown in Fig. 9 it may be seen that radiation induced a temporary block at the end of $S$ period, preventing cells from entering $G_{2}$ from $S$. When this block was overcome, cells irradiated with low doses of $\mathrm{X}$-rays progressed into $G_{2}$ at a rate greater than the nonirradiated cells. These results suggest that the rate of DNA synthesis of the cells near the end of $S$ period was affected to a greater extent than that of the cells irradiated in an earlier part of $S$ period. This differential sensitivity allows the cells irradiated at different parts of $S$ to complete DNA synthesis at the same time. Thus, the rate of flow of cells out of $S$ was greater than the control value. These data lend support to the hypothesis that the rates of DNA synthesis of cells in different parts of $S$ are affected to differing extents by radiation.

The percentage standard deviations calculated from data of the type shown in Fig. 4 were greater for the irradiated cultures than for the nonirradiated control culture. This increase in the percentage standard deviation can be explained on 
the basis of the proposed hypothesis. The different degrees of depression in DNA synthesis produced by ionizing radiation constituted a source of variation in addition to the inherent variation in a population of cells. This extra source of variation resulted in a greater percentage standard deviation.

The data presented in this paper indicate that the progress of cells through all parts of the division cycle affected by X-rays, but to different extents. For example, at 2 hours after 10,900 rads, the progress of cells from $S$ to $G_{2}$ was completely inhibited, the rate through $S$ was only $20 \%$ of the control, and the rate of flow of cells from $G_{1}$ to $S$ was still $50 \%$ of the control.

Thus, the effects of $\mathrm{X}$-rays on the L-cell cycle are complex. This complexity may be the result of damage to different processes in different periods of the cycle or due to damage to a process common to all periods, but manifested to a different extent in each period. It is not possible at present to distinguish between these alternatives.

\section{SUMMARY}

Many of the radiation effects on the mammalian cell cycle described by various workers using different cell systems have been demonstrated in a single cell culture strain, the subline L60TM of L-strain mouse cells. These effects are: (1) depression in the rate of progress of cells from the $G_{1}$ to the $S$ phase; $(2)$ depression of the rate of DNA synthesis shortly after irradiation; (3) recovery of rate of DNA synthesis at later times; (4) inhibition of progress of cells from $S$ to $G_{2}$ ( $S$ block); and (5) reversal of the $S$ block.

\section{ACKNOWLEDGMENTS}

We are grateful to Dr. W. R. Bruce for suggesting the use of 5-iodo-2'-deoxyuridine as a precursor of deoxyribonucleic acid, and to Dr. G. F. Whitmore for many helpful suggestions. This investigation was supported in part by a grant from the National Cancer Institute of Canada and in part by a research grant from the U.S. Public Health Service (PHS Grant C-6229). One of us (S.M.) held a Fellowship in Radiation Physics from the National Cancer Institute of Canada during the course of this work.

RECEIVED: March 22, 1963

\section{REFERENCES}

1. G. F. Whitmore, C. P. Stanners, J. E. Till, and S. Gulyas, Nucleic acid synthesis and the division cycle in X-irradiated L-strain mouse cells. Biochim. Biophys. Acta 47, 66-77 (1961).

2. J. E. Till, Radiation effects on the division cycle of mammalian cells in vitro. Ann. N.Y. Acad. Sci. 95, 911-919 (1961).

3. O.F. NygaARd and R. L. Potter, Effect of radiation on DNA metabolism in various tissues of the rat. Radiation Res. 16, 243-252 (1962).

4. L. G. Lajtha, R. Oliver, R. Berry, and W. D. Noyes, Mechanism of radiation effect on the process of synthesis of deoxyribonucleic acid. Nature 182, 1788-1790 (1958). 
5. F. G. Sherman and H. Quastler, DNA synthesis in irradiated intestinal epithelium. Exptl. Cell Res. 19, 343-360 (1960).

6. R. B. Painter, The direct effect of X-irradiation on HeLa S3 deoxyribonucleic acid synthesis. Radiation Res. 16, 846-859 (1962).

7. M. S. H. Dickson and J. Paul, Some effects of X-irradiation on the metabolism of deoxyribonucleic acid in mammalian cells grown in culture. Intern. J. Radiation Biol. 3, 419-429 (1961).

8. C. P. Stanners and J. E. Till, DNA synthesis in individual L-strain mouse cells. Biochim. Biophys. Acta 37, 406-419 (1960).

9. A. How ARD and S. R. Pelc, Synthesis of deoxyribonucleic acid in normal and irradiated cells and its relation to chromosome breakage. Heredity (Suppl.) 6, 261-273 (1953).

10. R. C. Parker, Methods of Tissue Culture, 3rd ed., Paul B. Hoeber, New York, 1961.

11. T. Alper, J. F. Fowler, R. L. Morgan, D. D. Vonberg, F. Ellis, and R. Oliver, The characterization of the "type C" survival curve. Brit. J. Radiol. 35, 722-723 (1962).

12. W. H. Prusoff, Synthesis and biological activities of iododeoxyuridine, an analog of thymidine. Biochim. Biophys. Acta 32, 295-296 (1959).

13. K. Burton, A study of the conditions and mechanism of the diphenylamine reaction for the colorimetric estimation of deoxyribonucleic acid. Biochem. J. 62, 315-323 (1956).

14. Report of the International Commission on Radiological Units and Measurements (ICRU) 1959. Natl. Bur. Std. (U.S.) 78, 54-58 (1961).

15. E. A. Hell, R. Berry, and L. G. Lajtha, A pitfall in high specific activity tracer studies. Nature 185, 47 (1960).

16. G. W. Snedecor, Statistical Methods, 5th ed., The Iowa State College Press, Ames, Iowa, 1956.

17. R. B. Painter and J. S. Robertson, Effect of irradiation and theory of role of mitotic delay on the time course of labeling of HeLa S3 cells with tritiated thymidine. Radiation Res. 11, 206-217 (1959).

18. H. Harrington, The effect of X-irradiation on the progress of strain U-12 fibroblasts through the mitotic cycle. Ann. N.Y. Acad. Sci. 95, 901-910 (1961).

19. L. G. Lajtha, R. Oliver, T. Kumatori, and F. Ellis, On the mechanism of radiation effect on DNA synthesis. Radiation Res. 8, 1-16 (1958).

20. T. Terasima and L. J. Tolmach, Variations in several responses of HeLa cells to X-irradiation during the division cycle. Biophys. J. 3, 11-33 (1963).

21. W. C. Dewey and R. M. Humphrey, Relative radiosensitivity of different phases in the life cycle of L-P59 mouse fibroblasts and ascites tumor cells. Radiation Res. 16, 503-530 (1962). 